\title{
The Role of the Gustatory System in the Coordination of Feeding
}

\author{
(1) Vladimiros Thoma, ${ }^{1,2}$ Kimiko Kobayashi, ${ }^{2}$ and Hiromu Tanimoto ${ }^{2}$
}

DOI:http://dx.doi.org/10.1523/ENEURO.0324-17.2017

${ }^{1}$ Department of Biology, Miyagi University of Education, Sendai, Miyagi 980-0845, Japan and ${ }^{2}$ Graduate School of

Life Sciences, Tohoku University, Sendai, Miyagi 980-8577, Japan

\section{Visual Abstract}

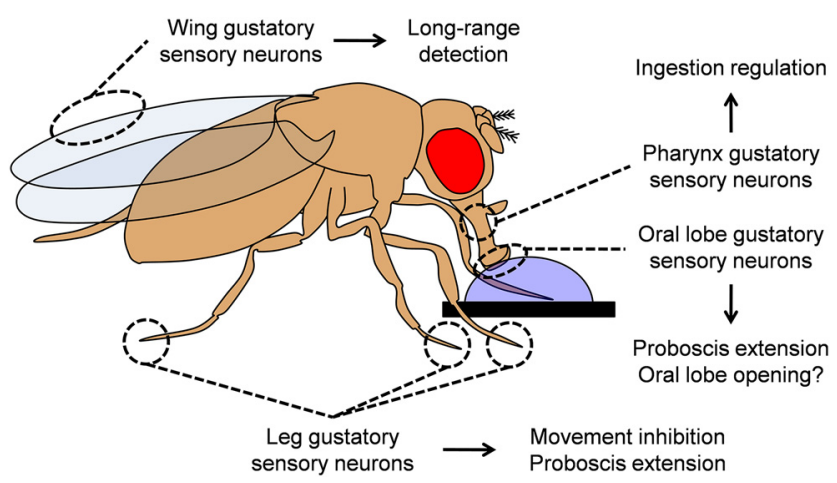

To survive, all animals must find, inspect, and ingest food. Behavioral coordination and control of feeding is therefore a challenge that animals must face. Here, we focus on how the gustatory system guides the precise execution of behavioral sequences that promote ingestion and suppresses competing behaviors. We summarize principles learnt from Drosophila, where underlying sensory neuronal mechanisms are illustrated in great detail. Moreover, we compare these principles with findings in other animals, where such coordination plays prominent roles. These examples suggest that the use of gustatory information for feeding coordination has an ancient origin and is prevalent throughout the animal kingdom.

Key words: coordination; evolution; feeding behavior; gustatory sensory neuron; neuroethology; taste

\section{Significance Statement}

Efficient feeding requires coordination. We synthesize findings across diverse species, highlighting the widespread and ancient role of taste in feeding coordination.

\section{Introduction}

All living organisms need energy to survive and reproduce. In contrast to plants and fungi, which rely on photosynthesis and absorption respectively, animals acquire energy by feeding on other organisms. As feeding behavior is essential for survival, animals have evolved special-

Received September 12, 2017; accepted October 25, 2017; First published November 10, 2017.

The authors declare no competing financial interests.

Author contributions: V.T., K.K., and H.T. wrote the paper.

This work was supported by the Deutsche Forschungsgemeinschaft Grant TA 552/5-1 (to H.T.); Ministry of Education, Culture, Sports, Science and Technology-Japan (MEXT)/Japanese Society for the Promotion of Science (JSPS)/JSPS KAKENHI Grants 26250001, 26120705, 17H01378, 17H05545, $16 \mathrm{H} 01496$, and $15 \mathrm{~K} 14307$ (to H.T.); the Naito Foundation (H.T.); and the Uehara Memorial Foundation (H.T.). V.T. is a JSPS International Research Fellow.

Acknowledgements: We thank Toshiharu Ichinose, Matthieu Louis, Pavel ized feeding structures such as mouths, teeth, tongues, and proboscises for food ingestion. These structures underlie equally diverse ingestion strategies. For example, many animals use their mouths to physically break down their food, others swallow their prey whole, and some feed by sucking nutritious fluids like nectar. Despite this diversity, food ingestion follows three general principles.

Masek, Shahaf Peleg, Reinhard Stocker, Teiichi Tanimura, and Nobuhiro Yamagata for comments on this manuscript and Anja Friedrich for technical support.

Correspondence should be addressed to Vladimiros Thoma, Department of Biology, Miyagi University of Education, Sendai, Miyagi 980-0845, Japan, E-mail: thoma-v@staff.miyakyo-u.ac.jp.

DOI:http://dx.doi.org/10.1523/ENEURO.0324-17.2017

Copyright (C) 2017 Thoma et al.

This is an open-access article distributed under the terms of the Creative Commons Attribution 4.0 International license, which permits unrestricted use, distribution and reproduction in any medium provided that the original work is properly attributed. 
(1) First, the animal must decide whether or not to accept a potential meal. (2) Upon acceptance, the animal must precisely execute behavioral sequences such as synchronized use of different effectors like jaws and tongues. (3) At the same time, competing behaviors like locomotion are often suppressed, so that the animal can focus on feeding. These two latter features ensure coordinated, efficient ingestion.

Sensory information, and especially taste, play critical roles in these three steps. Here, we focus on the gustatory control of steps (2) and (3), directing the reader to other reviews as to step (1) (Scott, 2005; Yarmolinsky et al., 2009; Liman et al., 2014; Joseph and Carlson, 2015). In his seminal review, published more than two decades ago, Reinhard Stocker provided a detailed description of the anatomy and physiology of the chemosensory system of Drosophila (Stocker, 1994). Based on these data, he hypothesized that the gustatory organs distributed throughout the body of the fruit fly have specialized functions. This idea has been remarkably substantiated by recent progress, which highlights the roles of distinct gustatory sensory neurons in regulating different aspects of feeding. Here, we review this progress and discuss the gustatory sensory mechanisms that underlie feeding coordination in other animals. By comparing the gustatory neuroethology of feeding in different animals, this review tries to extract common principles and discuss when these conserved systems evolved.

\section{Execution of Behavioral Sequences during Feeding}

To ingest food, humans and other primates use their hands to deliver it to their mouth (McGraw and Daegling, 2012). Consequently, chewing and secretion of saliva ensures that food is broken down physically and chemically. Once this is achieved, swallowing passes the food toward the alimentary canal for further digestion. Eventually, animals reach satiation and stop ingesting food. Similar behavioral sequences characterize the ingestion behaviors of many animals. Indeed, even "primitive" animals like jellyfish have a stereotyped sequence of feeding (Lindstedt, 1971b). Despite the prevalence of such sequences, the underlying sensory neuronal mechanisms that ensure their precise execution are not well understood.

Studies in insects provided important early contributions toward understanding the gustatory sensory control of feeding sequences. Unlike mammals, where the tongue is the main taste organ, insects have broadly distributed gustatory organs that include the legs, wings, genitalia, the surface and interior of the proboscis and, in some species, the antennae and maxillary palps (Stocker, 1994). In his influential book, Vincent Dethier provided detailed descriptions and studies of blowfly feeding behavior (Dethier, 1976). From a distance, a hungry blowfly relies on visual and olfactory cues to guide it toward potential food sources. When the blowfly eventually steps on food, it immediately stops, orients itself toward the food and extends its proboscis. Consequently, it opens its oral lobes (labella), located at the tip of the proboscis, and
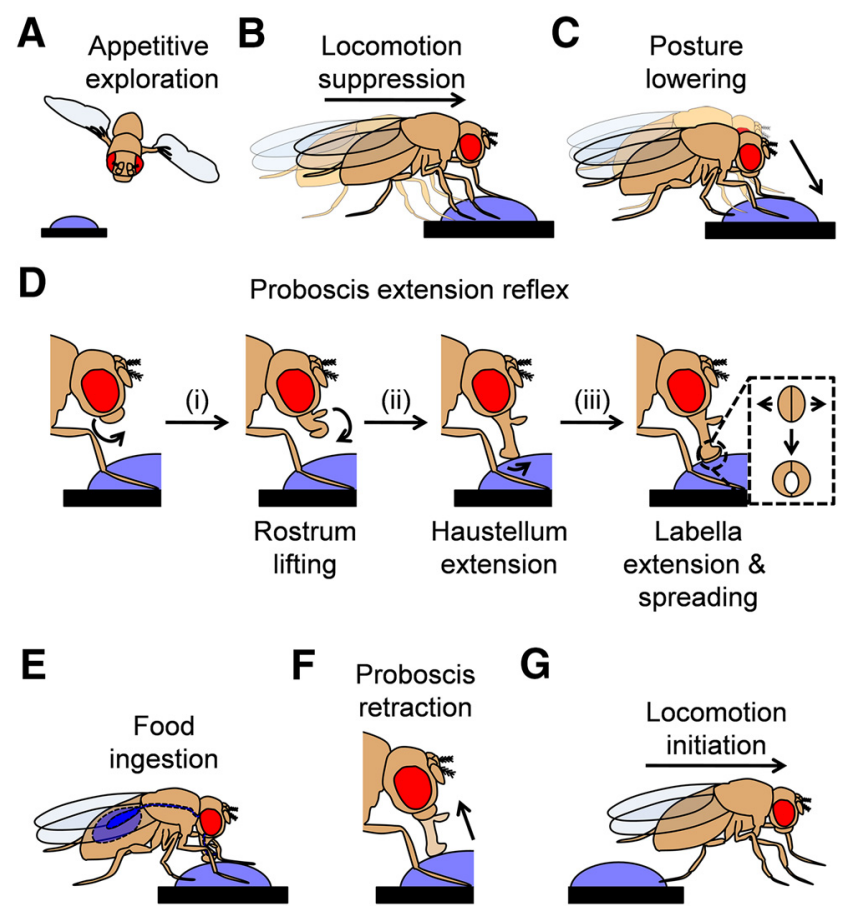

G

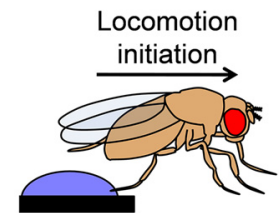

Figure 1. The feeding sequence of Drosophila. A, Initially, a hungry fly will search for food. This appetitive exploration relies on visual and chemical cues. As soon as the fly steps on food, it suppresses its movement $(\boldsymbol{B})$, lowers its posture $(\boldsymbol{C})$, and extends its proboscis $(\boldsymbol{D})$. The extension of the proboscis comprises of four steps that use different muscles (i-iii). A schematic of the surface of the proboscis, showing the spreading of the labella from below, is shown in the last step (inset). Consequently, $(E)$ the fly ingests food until satiated and then $(\boldsymbol{F})$ retracts its proboscis and $(\boldsymbol{G})$ moves away.

begins sucking food until it is satiated. Finally, the fly retracts its proboscis and eventually moves away, ignoring further encounters with food. When specific gustatory organs are stimulated, blowflies typically execute different subsets of feeding behavior (Pollack, 1977). Based on such observations, Dethier concluded that the legs control proboscis extension, while the gustatory hairs and gustatory pegs of the proboscis control the opening of its lobes and the sucking of food, respectively (Dethier, 1976). Chapman extended this observation to other insects (Chapman, 1995). Moreover, he argued that feeding sequences are not fixed, partly because gustatory organs early in the sequence can be overridden by more "downstream" organs. For example, grasshopper nymphs will lift their legs to avoid contact with a deterrent-covered leaf while eating it (White and Chapman, 1990). In blowflies, leg-driven proboscis extension is suppressed if an aversive substance is presented on the proboscis (Dethier et al., 1956). Despite their importance, these early studies did not have the resolution of individual neurons, leaving underlying neuronal mechanisms unanswered.

The advent of Drosophila neurogenetics has enabled targeted manipulation of neurons, allowing experiments that directly address their functions. Fruit flies and blowflies share a similar feeding sequence (Fig. 1; Pool and Scott, 2014) and gustatory system (Fig. 2A). Typically, the 
A

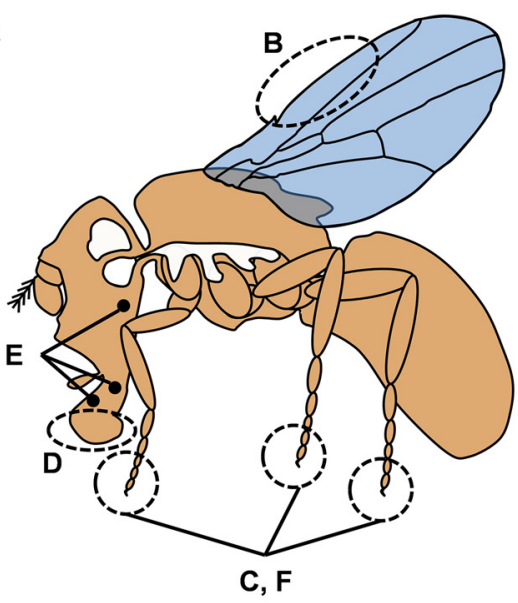

B

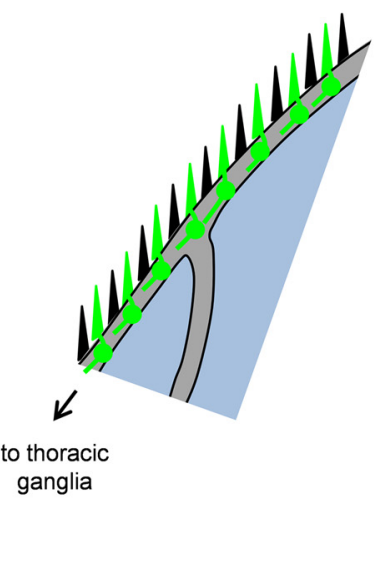

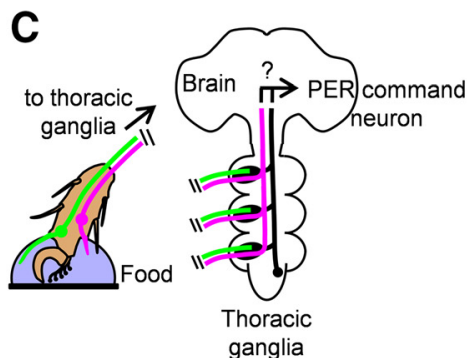

E
D

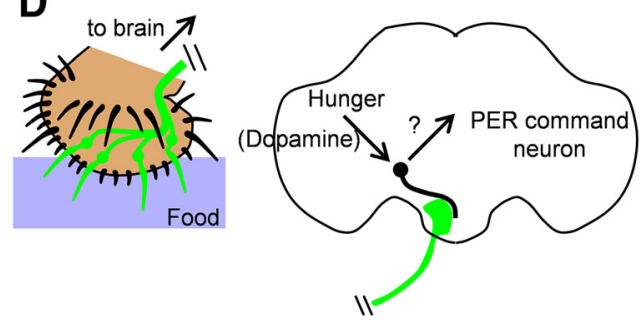

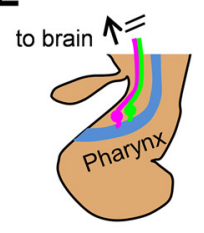

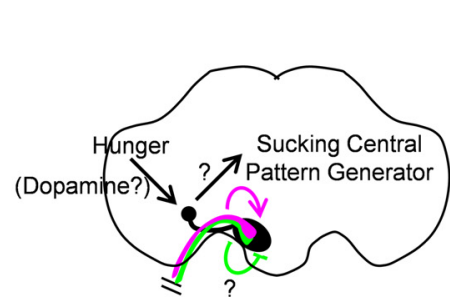

$\mathbf{F}$

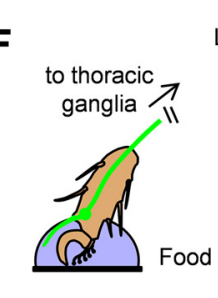

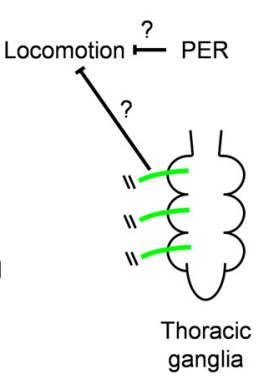

Figure 2. Neuronal circuits coordinating feeding in Drosophila. A, Schematic of an adult fruit fly, indicating the central nervous system, comprising of the brain and thoracic ganglia (white). The position of the gustatory organs (wings, tarsi, labella, and pharyngeal organs) are highlighted. $\boldsymbol{B}$, GRNs in the wings (green) are critical for long-range foraging. $\boldsymbol{C}$, Circuits controlling the PER on leg stimulation. Out of two groups of leg GRNs, brain-projecting GRNs (magenta) are more critical for PER, likely through more direct interactions with a brain command neuron. Locally-projecting GRNs (green) exert a smaller role, likely through SGNs (black). $\boldsymbol{D}$, Circuits controlling PER on labelar stimulation. Labelar GRNs (green) connect to SGNs in the brain (black) that integrate taste and hunger. $\boldsymbol{E}$, Circuits controlling food ingestion. Pharyngeal GRNs regulate feeding by prolonging (magenta cell) or decreasing (green cells) ingestion time. The sucking command neuron (black) directly receives information from pharyngeal GRNs, integrates it with hunger and likely activates the central pattern generator that controls pumping. $\boldsymbol{F}$, Circuits controlling locomotion suppression when feeding. Locally-projecting leg GRNs (green) suppress movement on food encounter. Proboscis extension also suppresses locomotion, although the underlying circuits are unknown. Question marks (?) indicate speculative or unknown pathways. For simplicity, only one or a few GRNs or SGNs per category are shown.

detection of food causes the aggregation of many fruit flies on it, both in nature and in the laboratory. Surprisingly, this aggregation is dramatically reduced when the gustatory receptor neurons (GRNs) in the wings (Fig. 2B, green) are specifically eliminated (Raad et al., 2016). The authors of this study propose that GRNs in the wings detect non-volatile chemicals in microdroplets, which are produced by flying over liquids, and can therefore facilitate appetitive exploration (Fig. 1A). Once the flies land on food, additional gustatory organs can be stimulated. Like in blowflies, stimulating GRNs in the legs of hungry fruit flies with food (Fig. 2C) elicits the proboscis extension reflex (PER; Fig. 1D). PER can also occur after stimulation of the labelar gustatory hairs (Fig. 2D; Shiraiwa and Carl- son, 2007). Spontaneous proboscis responses have also been reported (Fujita and Tanimura, 2011), but they are very infrequent (Mann et al., 2013) and less likely to proceed to full extension in wild-type flies (Chabaud et al., 2006). Such responses may be of lesser importance under normal circumstances, as the legs typically contact the food first. Leg-driven PER is controlled by a small group of highly sensitive sugar GRNs, located in the tip of each leg (Fig. 2C, magenta; Miyamoto et al., 2013; Ling et al., 2014; Thoma et al., 2016). They are likely to constantly evaluate potential food during walking. Moreover, they project directly to the brain, ensuring rapid proboscis extension as soon as food is detected. Such anatomical and physiological properties likely evolved 
to support a specialized and crucial role in the initiation of feeding.

Detailed examination of the PER reveals that it can be broken down to four sequential steps, namely lifting of the rostrum, extension of the haustellum and extension and spreading of the labella (Fig. 1D). These steps are independent: later steps can be induced without earlier steps (Schwarz et al., 2017), showing that the effectors within the proboscis are not organized as a chain reaction, but rather centrally coded via "command" interneurons (Flood et al., 2013). Interestingly, at least one step, the spreading of the labella (Fig. $1 D$, inset), was elicited more robustly by labelar rather than tarsal stimulation, in line with findings in the blowfly (Pollack, 1977). Such differences in effectiveness may enable fine-tuning of the feeding response based on positional information, in the case of a highly localized appetitive stimulus.

After the proboscis is extended, flies start to ingest food (Fig. 1E), bringing it into contact with pharyngeal GRNs (Fig. 2E), which are in close proximity with the central pattern generator that generates sucking behavior (Manzo et al., 2012). Pharyngeal GRNs regulate food consumption by influencing the duration of ingestion (LeDue et al., 2015; Joseph et al., 2017). Surprisingly, two populations of sugar-sensitive pharyngeal GRNs have opposite effects on consumption: a group of gustatory receptorexpressing cells promotes it (LeDue et al., 2015), while a pair of ionotropic receptor-expressing cells inhibits it (Fig. $2 E$, magenta and green, respectively; Joseph et al., 2017). The ionotropic receptor-expressing cells were proposed to prevent overconsumption following prolonged ingestion, because their calcium responses are slower than those of the gustatory receptor-expressing cells (Joseph et al., 2017). Interestingly, following the ingestion of a small amount of sugar solution, flies execute a local appetitive search, a behavior also controlled by pharyngeal GRNs (Murata et al., 2017). Taken together, these findings emphasize the role of highly specialized GRNs in the execution of the Drosophila feeding sequence and in the precise control of each step.

Because Drosophila feeding responses are not simple monosynaptic reflexes (Gordon and Scott, 2009), the specialized functions of GRNs are likely enacted by central neurons. Recent studies have identified several secondorder gustatory neurons (SGNs) that receive direct input from GRNs and control different aspects of feeding (Fig. 2C-E; Kain and Dahanukar, 2015; Miyazaki et al., 2015; Yapici et al., 2016; Kim et al., 2017). For example, two sets of SGNs in the thoracic ganglia receive input from sugar GRNs in the legs and their activation is sufficient, but not necessary, to elicit PER (Fig. 2C, black; Kim et al., 2017). This suggests redundancy in the neuronal pathways controlling this behavior, in line with findings about the corresponding leg GRNs (Thoma et al., 2016). Interestingly, two different groups of brain SGNs were recently shown to control distinct aspects of the feeding sequence. The first group receives input from labelar GRNs and controls PER (Fig. 2D, black; Kain and Dahanukar, 2015), while the second group receives input from pharyngeal GRNs and controls ingestion (Fig. 2E, black; Yapici et al., 2016). Both
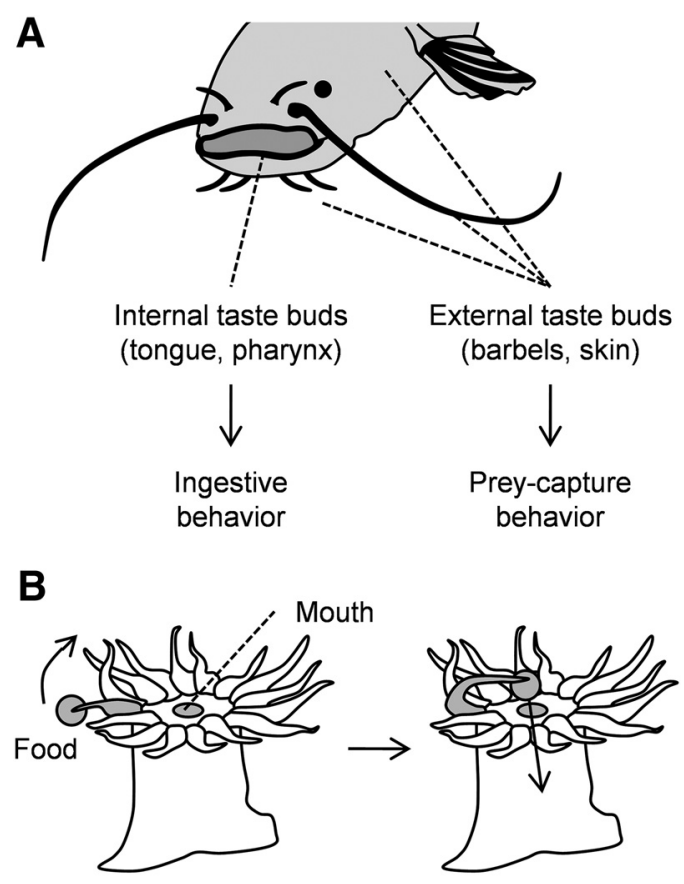
Tentacle contraction and bending (Asparagine)

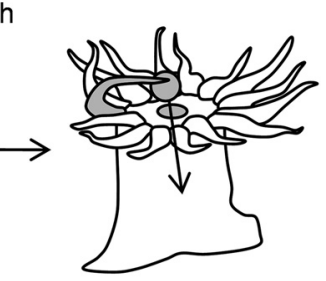

Figure 3. The role of gustatory information in the feeding coordination of catfish and sea anemones. $\boldsymbol{A}$, Catfish have external and internal taste buds. The former control prey-capture behaviors, while the latter control ingestive behaviors such as chewing and swallowing. B, The sea anemone Anthopleura captures food (gray circle) with its tentacles, brings it to its mouth, and swallows it. Asparagine and glutathione, likely released from sting-injured prey, control tentacle movements and swallowing, respectively.

groups not only enact the functions of their associated GRNs, but also integrate gustatory information with starvation state, the latter likely being conveyed to them by dopaminergic circuits (Inagaki et al., 2012; Marella et al., 2012). Future studies will be useful to place additional feeding interneurons (Flood et al., 2013; Mann et al., 2013; Pool et al., 2014) in the broader context of these established gustatory neuronal circuits.

Although gustatory information is critical for feeding, nutritional needs and the caloric content of food also play important roles. Nutritional needs are coded by central neurons, which determine the substances to be ingested (Bjordal et al., 2014; Jourjine et al., 2016). Importantly, because nutrients can reach the brain within seconds of feeding initiation (Itskov et al., 2014), caloric information can be used in real-time to regulate ingestion (Qi et al., 2015). This is accomplished by brain neurons, some of which express gustatory receptors (Miyamoto et al., 2012; Dus et al., 2013). For example, brain neurons expressing a fructose receptor detect this sugar in the hemolymph, and are involved in ingestion regulation and appetitive learning (Miyamoto et al., 2012). The presence of nutrientdetecting pathways is likely advantageous to flies, as some naturally occurring sugars are sweet but offer no nutrition. These findings demonstrate that there are com- 
A

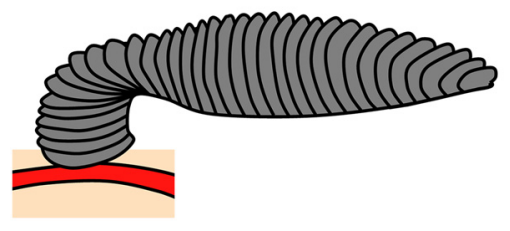

Blood $\rightarrow \underset{\text { Densory neurons }}{\text { Dorsap }} \rightarrow \rightarrow \begin{aligned} & \text { Serotonergic } \\ & \text { interneurons }\end{aligned}$

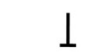

Nociceptive

neurons
B
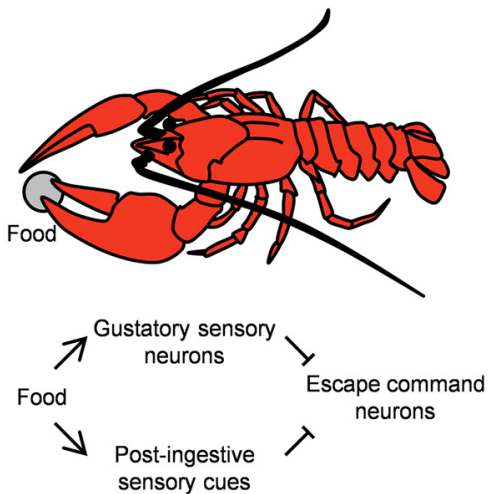

Figure 4. Neuronal circuits underlying suppression of escape responses during feeding in leeches and crayfish. $\boldsymbol{A}$, In leeches, stimulation of taste sensory neurons in the lip inhibits nociceptive neurons through serotonergic interneurons. $\boldsymbol{B}$, In crayfish, taste and postingestive information suppresses the escape command neurons.

plex interactions between taste, hunger, caloric content and nutritional needs, and they are crucial for the tight regulation of feeding.

\section{Feeding Sequences of Other Animals}

Like insects, many aquatic animals have taste sensors that are widely distributed over their body. In several cases, these have been shown to play different roles in feeding behavior. Catfish provide a striking example. They have taste buds not only in their mouth and pharynx, but also on their entire body surface, and are often described as "swimming tongues" (Caprio et al., 1993). Their surface taste buds are involved in capturing prey with their mouth, while internal taste buds control chewing and swallowing (Fig. 3A; Atema, 1971). Other aquatic animals also have multiple taste organs. In blue crabs and leeches engaged in feeding, the rejection of aversive tastants is controlled by internal, and not external, taste sensors (Kornreich and Kleinhaus, 1999; Aggio et al., 2012). In lobsters, taste sensors in the legs are required for a food-clasping response (Borroni et al., 1986). Although the functions of taste organs are not always clear, these examples show that they are often specialized.

Jellyfish and anemones belong to the phylum Cnidaria, which represents one of the most basal animal phyla with nervous systems. They typically capture prey with stingequipped tentacles and consequently transfer it to the mouth for swallowing and digestion. In the freshwater polyp Hydra, tentacle retraction and mouth opening are triggered by the small peptide glutathione, presumably released from sting-injured prey (Loomis, 1955). After swallowing, the mouth constricts to form a "neck" that prevents prey escape, a behavior controlled by tyrosine, which is detected inside the mouth (Blanquet and Lenhoff, 1968). In the sea anemone Anthopleura, tentacle bending and ingestion are controlled by asparagine and glutathione, respectively (Fig. 3B; Lindstedt, 1971a). In the jellyfish Aglantha, orientation of the mouth toward tentacle-captured prey and engulfing lip movements, which promote ingestion, are controlled by distinct conduction pathways (Mackie et al., 2003), although gustatory signals that activate these pathways are unknown. These examples suggest that coordination of feeding through multiple gustatory sensors has ancient origins.
How is feeding coordinated in animals with centralized taste systems, like mammals? In mice, starvation alters the activity of hypothalamic circuits, which causes animals to forage for food. The sensory detection of food resets activity in these circuits, inhibiting foraging and facilitating the transition to ingestive behaviors (Chen et al., 2015). However, the specific role of taste information in these circuits was not investigated in detail. The initiation of ingestion, namely food delivery to the mouth, must rely on other sensory modalities, as mammals lack external taste sensors. However, taste sensory cells in the mouth may play different roles in later phases of ingestion. For example, like in fruit flies, pharyngeal taste sensors in mammals may be important for swallowing (Yapici et al., 2016). Spector and Glendinning suggest that the vertebrate taste system serves three functions: stimulus identification, ingestive motivation and digestive preparation. They speculate that different taste afferent inputs control these different functions (Spector and Glendinning, 2009). Future research is awaited to examine this hypothesis.

\section{Suppression of Competing Behaviors during Feeding}

Feeding is typically incompatible with other behaviors. For example, when feeding on blood, leeches can endure aversive chemicals applied to the animal's chemosensory organ (Kornreich and Kleinhaus, 1999) and electric shocks (Gaudry et al., 2010). Strikingly, highly dissected leeches lacking a body wall and internal organs will still initiate and commit to feeding, showing that they can even ignore severe trauma to obtain a meal (Gaudry and Kristan, 2009). Such remarkable concentration on feeding is observed in many other animals including jellyfish (Mackie et al., 2003), crayfish (Krasne and Lee, 1988), mollusks (Davis et al., 1977; Advokat, 1980; Kovac and Davis, 1980; Norekian and Satterlie, 1996), and insects (Mann et al., 2013; Thoma et al., 2016). Despite the widespread occurrence of this phenomenon, the underlying sensory mechanisms are only partially understood.

In his classical studies, Dethier observed that hungry blowflies, upon encountering food, will immediately stop walking (Dethier, 1976). Because the initial food contact 
must be made with the leg, before other gustatory organs are stimulated, leg GRNs likely control this behavior. The specific gustatory mechanisms underlying food-induced locomotion suppression have been recently elucidated in Drosophila (Mann et al., 2013; Thoma et al., 2016). Fruit flies have two anatomically distinct sugar GRNs in the legs: some project directly to the brain, whereas the rest project locally to the thoracic ganglia (Fig. $2 \mathrm{C}$, magenta and green, respectively). The locally projecting neurons are specifically required for locomotion suppression (Thoma et al., 2016), most likely by influencing the motor neurons controlling leg movements, which are also located in the thoracic ganglia (Fig. 2F, green; Tuthill and Wilson, 2016). Moreover, when the fruit fly starts to feed, the extension of the proboscis itself inhibits locomotion via as yet unidentified circuits (Mann et al., 2013). Therefore, two dedicated neuronal mechanisms ensure that locomotion is inhibited not only as an initial response to food, but also throughout ingestion.

In the Drosophila larva, activation of a small set of interneurons expressing the neuropeptide hugin suppresses feeding and initiates locomotion, providing the basis for the mutual exclusivity of these competing behaviors (Schoofs et al., 2014). The dendrites of the hugin-expressing neurons are in close proximity to the GRN axon terminals, and their axons project to pharyngeal muscles (Melcher and Pankratz, 2005). This strongly suggests that gustatory information, by directly acting on hugin neurons, is critical for choosing whether to feed or move in the larva. Taken together, these results highlight Drosophila as a wellestablished model system for understanding the gustatory and neuronal mechanisms that govern the behavioral switch towards feeding.

Many other animals can suppress competing behaviors when feeding. In crayfish, mollusks and leeches, painful stimuli elicit defensive responses such as escape, but these are suppressed in the presence of food or when feeding (Davis et al., 1977; Advokat, 1980; Kovac and Davis, 1980; Krasne and Lee, 1988; Gaudry and Kristan, 2009). Behavioral and electrophysiological studies highlight two opposing mechanisms that underlie this suppression (Fig. 4). In leeches, blood stimulates chemosensory neurons in the lip, which in turn inhibit the nociceptive neurons, likely through serotonergic interneurons. The escape command neurons remain unaffected (Fig. 4A; Gaudry and Kristan, 2009, 2012). In contrast, in crayfish and in mollusks, food and postingestive stimuli inhibit the escape command neurons (Fig. 4B; Davis et al., 1977; Kovac and Davis, 1980; Krasne and Lee, 1988). These opposing mechanisms may underlie different food requirements or feeding habits. Such circuits should be able to "weigh" appetitive and aversive stimuli in the context of the animal's hunger state, and carry out the cost-benefit analysis necessary for adaptive behavior.

\section{Conclusions}

Feeding behavior is essential for all animals and it has played a critical role in shaping their evolution. Nervous systems may have evolved to facilitate more efficient feeding (Arendt et al., 2015), predation or predation avoidance (Kristan, 2016). Because chemosensation has an- cient origins that trace back to bacteria (Baluska and Mancuso, 2009), taste sensory neurons were most likely important for improving feeding efficiency from an early stage. The examples provided here highlight the important role of taste in coordinating feeding in several animal species. However, our understanding of feeding neuroethology still remains limited to a handful of organisms. To understand the evolution of the neural circuits underlying feeding, we must first expand our knowledge to a broader set of animals that better captures the full diversity of the animal kingdom.

\section{References}

Advokat C (1980) Modulation of defensive reflexes in Aplysia californica by appetitive stimulation. Behav Neural Biol 28:253-265. Medline

Aggio JF, Tieu R, Wei A, Derby CD (2012) Oesophageal chemoreceptors of blue crabs, Callinectes sapidus, sense chemical deterrents and can block ingestion of food. J Exp Biol 215:1700-1710. CrossRef Medline

Arendt D, Benito-Gutierrez E, Brunet T, Marlow H (2015) Gastric pouches and the mucociliary sole: setting the stage for nervous system evolution. Philos Trans R Soc Lond B Biol Sci 370:CrossRef

Atema J (1971) Structures and functions of the sense of taste in the catfish (Ictalurus natalis). Brain Behav Evol 4:273-294. Medline

Baluska F, Mancuso S (2009) Deep evolutionary origins of neurobiology: turning the essence of 'neural' upside-down. Commun Integr Biol 2:60-65. Medline

Bjordal M, Arquier N, Kniazeff J, Pin JP, Léopold P (2014) Sensing of amino acids in a dopaminergic circuitry promotes rejection of an incomplete diet in Drosophila. Cell 156:510-521. CrossRef

Blanquet RS, Lenhoff HM (1968) Tyrosine enteroreceptor of Hydra: its function in eliciting a behavior modification. Science 159:633634. Medline

Borroni PF, Handrich LS, Atema J (1986) The role of narrowly tuned taste cell populations in lobster (Homarus americanus) feeding behavior. Behav Neurosci 100:206-212. Medline

Caprio J, Brand JG, Teeter JH, Valentincic T, Kalinoski DL, Kohbara J, Kumazawa T, Wegert S (1993) The taste system of the channel catfish: from biophysics to behavior. Trends Neurosci 16:192-197. Medline

Chabaud MA, Devaud JM, Pham-Delègue MH, Preat T, Kaiser L (2006) Olfactory conditioning of proboscis activity in Drosophila melanogaster. J Comp Physiol A Neuroethol Sens Neural Behav Physiol Neuroethol Sens Neural Behav Physiol 192:1335-1348. CrossRef Medline

Chapman RF (1995) Chemosensory regulation of feeding. In: Regulatory mechanisms in insect feeding (Chapman RF, de Boer G, eds), pp 101-136. New York: Springer.

Chen Y, Lin YC, Kuo TW, Knight ZA (2015) Sensory detection of food rapidly modulates arcuate feeding circuits. Cell 160:829-841. CrossRef Medline

Davis WJ, Mpitsos GJ, Michael Pinneo J, Ram JL (1977) Modification of the behavioral hierarchy of Pleurobranchaea. J Comp Physiol 117:99-125. CrossRef

Dethier VG (1976) The hungry fly: a physiological study of the behavior associated with feeding. Cambridge: Harvard University Press.

Dethier VG, Evans DR, Rhoades MV (1956) Some factors controlling the ingestion of carbohydrates by the blowfly. Biol Bull 111:204222. CrossRef

Dus M, Ai M, Suh GS (2013) Taste-independent nutrient selection is mediated by a brain-specific $\mathrm{Na}+$ /solute co-transporter in Drosophila. Nat Neurosci 16:526-528. CrossRef

Flood TF, Iguchi S, Gorczyca M, White B, Ito K, Yoshihara M (2013) A single pair of interneurons commands the Drosophila feeding motor program. Nature 499:83-87. CrossRef Medline 
Fujita M, Tanimura T (2011) Drosophila evaluates and learns the nutritional value of sugars. Curr Biol 21:751-755. CrossRef Medline

Gaudry Q, Kristan WB Jr (2009) Behavioral choice by presynaptic inhibition of tactile sensory terminals. Nat Neurosci 12:1450-1457. CrossRef Medline

Gaudry Q, Kristan WB Jr (2012) Decision points: the factors influencing the decision to feed in the medicinal leech. Front Neurosci 6:101. CrossRef

Gaudry Q, Ruiz N, Huang T, Kristan WB 3rd, Kristan WB Jr (2010) Behavioral choice across leech species: chacun a son gout. J Exp Biol 213:1356-1365. CrossRef Medline

Gordon MD, Scott K (2009) Motor control in a Drosophila taste circuit. Neuron 61:373-384. CrossRef

Inagaki HK, Ben-Tabou de-Leon S, Wong AM, Jagadish S, Ishimoto H, Barnea G, Kitamoto T, Axel R, Anderson DJ (2012) Visualizing neuromodulation in vivo: TANGO-mapping of dopamine signaling reveals appetite control of sugar sensing. Cell 148:583-595. CrossRef Medline

Itskov PM, Moreira JM, Vinnik E, Lopes G, Safarik S, Dickinson MH, Ribeiro C (2014) Automated monitoring and quantitative analysis of feeding behaviour in Drosophila. Nat Commun 5:4560. CrossRef Medline

Joseph RM, Carlson JR (2015) Drosophila chemoreceptors: a molecular interface between the chemical world and the brain. Trends Genet 31:683-695. CrossRef Medline

Joseph RM, Sun JS, Tam E, Carlson JR (2017) A receptor and neuron that activate a circuit limiting sucrose consumption. Elife 6.

Jourjine N, Mullaney BC, Mann K, Scott K (2016) Coupled sensing of hunger and thirst signals balances sugar and water consumption. Cell 166:855-866. CrossRef Medline

Kain P, Dahanukar A (2015) Secondary taste neurons that convey sweet taste and starvation in the Drosophila brain. Neuron 85:819832. CrossRef Medline

Kim H, Kirkhart C, Scott K (2017) Long-range projection neurons in the taste circuit of Drosophila. Elife 6.

Kornreich L, Kleinhaus AL (1999) Postingestive chemosensation and feeding by leeches. Physiol Behav 67:635-641. Medline

Kovac MP, Davis WJ (1980) Neural mechanism underlying behavioral choice in Pleurobranchaea. J Neurophysiol 43:469-487. Medline

Krasne F, Lee S (1988) Response-dedicated trigger neurons as control points for behavioral actions: selective inhibition of lateral giant command neurons during feeding in crayfish. J Neurosci 8:3703-3712. Medline

Kristan WB Jr (2016) Early evolution of neurons. Curr Biol 26:R949R954. CrossRef Medline

LeDue EE, Chen YC, Jung AY, Dahanukar A, Gordon MD (2015) Pharyngeal sense organs drive robust sugar consumption in Drosophila. Nat Commun 6:6667. CrossRef Medline

Liman ER, Zhang YV, Montell C (2014) Peripheral coding of taste. Neuron 81:984-1000. CrossRef Medline

Lindstedt KJ (1971a) Biphasic feeding response in a sea anemone: control by asparagine and glutathione. Science 173:333-334. CrossRef Medline

Lindstedt KJ (1971b) Chemical control of feeding behavior. Comp Biochem Physiol A Comp Physiol 39:553-581. Medline

Ling F, Dahanukar A, Weiss LA, Kwon JY, Carlson JR (2014) The molecular and cellular basis of taste coding in the legs of Drosophila. J Neurosci 34:7148-7164. CrossRef Medline

Loomis WF (1955) Glutathione control of the specific feeding reactions of Hydra. Ann NY Acad Sci 62:211-227. CrossRef

Mackie GO, Marx RM, Meech RW (2003) Central circuitry in the jellyfish Aglantha digitale IV. Pathways coordinating feeding behaviour. J Exp Biol 206:2487-2505. Medline

Mann K, Gordon MD, Scott K (2013) A pair of interneurons influences the choice between feeding and locomotion in Drosophila. Neuron 79:754-765. CrossRef Medline

Manzo A, Silies M, Gohl DM, Scott K (2012) Motor neurons controlling fluid ingestion in Drosophila. Proc Natl Acad Sci USA 109: 6307-6312. CrossRef Medline
Marella S, Mann K, Scott K (2012) Dopaminergic modulation of sucrose acceptance behavior in Drosophila. Neuron 73:941-950. CrossRef Medline

McGraw WS, Daegling DJ (2012) Primate feeding and foraging: integrating studies of behavior and morphology. Annu Rev Anthropol 41:24. CrossRef

Melcher C, Pankratz MJ (2005) Candidate gustatory interneurons modulating feeding behavior in the Drosophila brain. PLoS Biol 3:e305. CrossRef Medline

Miyamoto T, Slone J, Song X, Amrein H (2012) A fructose receptor functions as a nutrient sensor in the Drosophila brain. Cell 151: 1113-1125. CrossRef Medline

Miyamoto T, Chen Y, Slone J, Amrein H (2013) Identification of a Drosophila glucose receptor using $\mathrm{Ca} 2+$ imaging of single chemosensory neurons. PLoS One 8:e56304. CrossRef Medline

Miyazaki T, Lin TY, Ito K, Lee CH, Stopfer M (2015) A gustatory second-order neuron that connects sucrose-sensitive primary neurons and a distinct region of the gnathal ganglion in the Drosophila brain. J Neurogenet 29:144-155. CrossRef

Murata S, Brockmann A, Tanimura T (2017) Pharyngeal stimulation with sugar triggers local searching behavior in Drosophila. J Exp Biol 220:3231-3237. CrossRef Medline

Norekian TP, Satterlie RA (1996) Whole body withdrawal circuit and its involvement in the behavioral hierarchy of the mollusk Clione limacina. J Neurophysiol 75:529-537. Medline

Pollack GS (1977) Labellar lobe spreading in the blowfly: regulation by taste and satiety. J Comp Physiol 121:115-134. CrossRef

Pool AH, Scott K (2014) Feeding regulation in Drosophila. Curr Opin Neurobiol 29:57-63. CrossRef Medline

Pool AH, Kvello P, Mann K, Cheung SK, Gordon MD, Wang L, Scott K (2014) Four GABAergic interneurons impose feeding restraint in Drosophila. Neuron 83:164-177. CrossRef Medline

Qi W, Yang Z, Lin Z, Park JY, Suh GS, Wang L (2015) A quantitative feeding assay in adult Drosophila reveals rapid modulation of food ingestion by its nutritional value. Mol Brain 8:87. CrossRef Medline

Raad H, Ferveur JF, Ledger N, Capovilla M, Robichon A (2016) Functional gustatory role of chemoreceptors in Drosophila wings. Cell Rep 15:1442-1454. CrossRef Medline

Schoofs A, Hückesfeld S, Schlegel P, Miroschnikow A, Peters M, Zeymer M, Spieß R, Chiang AS, Pankratz MJ (2014) Selection of motor programs for suppressing food intake and inducing locomotion in the Drosophila brain. PLoS Biol 12:e1001893. CrossRef Medline

Schwarz O, Bohra AA, Liu X, Reichert H, VijayRaghavan K, Pielage J (2017) Motor control of Drosophila feeding behavior. Elife 6:CrossRef

Scott K (2005) Taste recognition: food for thought. Neuron 48:455464. CrossRef Medline

Shiraiwa T, Carlson JR (2007) Proboscis extension response (PER) assay in Drosophila. J Vis Exp 193.

Spector AC, Glendinning Jl (2009) Linking peripheral taste processes to behavior. Curr Opin Neurobiol 19:370-377. CrossRef Medline

Stocker RF (1994) The organization of the chemosensory system in Drosophila melanogaster: a review. Cell Tissue Res 275:3-26. Medline

Thoma V, Knapek S, Arai S, Hartl M, Kohsaka H, Sirigrivatanawong $\mathrm{P}$, Abe A, Hashimoto K, Tanimoto H (2016) Functional dissociation in sweet taste receptor neurons between and within taste organs of Drosophila. Nat Commun 7:10678. CrossRef Medline

Tuthill JC, Wilson RI (2016) Mechanosensation and adaptive motor control in insects. Curr Biol 26:R1022-R1038. CrossRef Medline

White PR, Chapman RF (1990) Tarsal chemoreception in the polyphagous grasshopper Schistocerca americana: behavioural assays, sensilla distributions and electrophysiology. Physiol Entomol 15:105-121. CrossRef

Yapici N, Cohn R, Schusterreiter C, Ruta V, Vosshall LB (2016) A taste circuit that regulates ingestion by integrating food and hunger signals. Cell 165:715-729. CrossRef Medline

Yarmolinsky DA, Zuker CS, Ryba NJ (2009) Common sense about taste: from mammals to insects. Cell 139:234-244. CrossRef Medline 